\title{
Vitreoretinal surgery for macular hole after laser assisted in situ keratomileusis for the correction of myopia
}

\author{
J F Arevalo, F J Rodriguez, J L Rosales-Meneses, A Dessouki, C K Chan, R A Mittra, J M Ruiz- \\ Moreno
}

Br J Ophthalmol 2005;89:1423-1426. doi: 10.1136/bjo.2005.074542

\begin{abstract}
Ams: To describe the characteristics and surgical outcomes of full thickness macular hole surgery after laser assisted in situ keratomileusis (LASIK) for the correction of myopia.

Methods: 13 patients (14 eyes) who developed a macular hole after bilateral LASIK for the correction of myopia participated in the study.

Results: Macular hole formed 1-83 months after LASIK (mean 13 months). 11 out of $13(84.6 \%)$ patients were female. Mean age was 45.5 years old (25-65). All eyes were myopic (range -0.50 to -19.75 dioptres (D); mean -8.4 D). Posterior vitreous detachment (PVD) was not present before and was documented after LASIK on $42.8 \%$ of eyes. Most macular hole were unilateral, stage 4 macular hole, had no yellow deposits on the retinal pigment epithelium, had no associated epiretinal membrane, were centric, and had subretinal fluid. The mean diameter of the hole was $385.3 \mu \mathrm{m}$ (range 200-750 $\mu \mathrm{m}$ ). A vitrectomy closed the macular hole on all eyes with an improvement on final best corrected visual acuity (VA) on 13 out of 14 (92.8\%) patients.

Conclusions: This study shows that vitreoretinal surgery can be successful in restoring vision for most myopic eyes with a macular hole after LASIK.
\end{abstract}

a aser assisted in situ keratomileusis (LASIK) has become one of the most popular options for the correction of low Lto moderate myopia worldwide. ${ }^{1}$ However, vitreoretinal complications including endophthalmitis, retinal tear and detachment, retinal haemorrhage, and choroidal neovascular membrane have been reported. ${ }^{2-9}$

Chan and Lawrence ${ }^{10}$ have reported three eyes of three myopic patients that developed a macular hole in one eye after bilateral LASIK or photorefractive keratectomy (PRK). Ruiz-Moreno et al ${ }^{1112}$ recently reported a case of a macular hole in a myopic eye after LASIK. We previously reported in a letter to the editor 10 eyes ( 10 patients) with full thickness macular hole development after bilateral LASIK for the correction of ametropia. ${ }^{13}$

This report describes the characteristics, and surgical outcomes in 13 patients ( 14 eyes) who developed a macular hole after bilateral LASIK for the correction of myopia.

\section{METHODS}

Institutional ethics committee approval and informed consent were obtained for this study. In addition, the study was performed in accordance with the 1964 Declaration of Helsinki. We reviewed the medical records and obtained follow up information on all consecutive patients in our files with full thickness macular hole after LASIK and who subsequently underwent vitreoretinal surgery to repair the macular hole between March 1996 and March 2003 at seven institutions in Venezuela, Colombia, Spain, and the United States. Preoperative examination including a thorough dilated funduscopy with indirect ophthalmoscopy, and slit lamp biomicroscopy was performed by a retina specialist and/ or a refractive surgeon. Patients were female in $60.7 \%$ of cases, and underwent surgical correction of myopia ranging from -0.75 to -29.00 dioptres (D) (mean -6.19 D). Patients were followed for a mean of 65 months after LASIK (range 6-84 months). Patients who underwent vitreoretinal surgery to repair the macular hole were included in the study independent of the length of follow up.

Before LASIK, a retina specialist and/or a refractive surgeon performed contact or non-contact biomicroscopic evaluation of the fundus to determine posterior vitreous status. After LASIK, a retina specialist performed contact or non-contact biomicroscopic evaluation of the fundus to determine posterior vitreous status and macular hole characteristics. The presence of a Weiss ring was an important index for diagnosing a posterior vitreous detachment (PVD). The data were collected from the clinical records and/or operative reports. Optical coherence tomography (OCT) was used after LASIK by the retina specialist to confirm the macular hole, and its characteristics. In addition, OCT was used after vitrectomy to confirm the status of the macular hole.

Vitrectomy was used to repair the macular hole in all cases with gas $\left(\mathrm{C}_{3} \mathrm{~F}_{8}(\mathrm{n}=6)\right.$ or $\left.\mathrm{SF}_{6}(\mathrm{n}=6)\right)$, and prone positioning. In two patients silicone oil was used for internal tamponade because of the inability to tolerate prolonged face down positioning. A mechanical posterior hyaloid detachment was created in those cases with a stage 2 or 3 macular hole. In addition, internal limiting membrane peeling was performed in only four of our cases with trypan blue (MembraneBlue, Dorc International bv, Zuidland, Netherlands) or indocyanine green (IC green, Akorn Inc, Decatur, IL, USA) staining.

\section{RESULTS}

We found 14 eyes (13 patients) with full thickness macular hole after LASIK. The macular hole formed 1-83 months after LASIK (mean 13 months). In $57.1 \%$ of cases it developed $\leqslant 6$ months after LASIK, and in $28.5 \%$ of cases it developed 1 year or more after LASIK. Eleven (84.6\%) patients were female. The mean age was 45.5 years old (range 25-65 years). All eyes with macular hole after LASIK were myopic (range -0.50 to $-19.75 \mathrm{D}$; mean $-8.4 \mathrm{D}$ ). Posterior vitreous detachment was not present before and was documented after LASIK in $42.8 \%$ of eyes (table 1 ). A vitrectomy was performed at a mean of 60 days (range 1 day

Abbreviations: IC, indocyanine; LASIK, laser assisted in situ keratomileusis; OCT, optical coherence tomography; PRK, photorefractive keratectomy; PVD, posterior vitreous detachment; VA, visual acuity 
Table 1 Clinical findings of patients with surgery for macular holes after LASIK (14 eyes)

\begin{tabular}{|c|c|c|c|c|c|c|c|c|c|c|c|c|c|c|}
\hline Patient & Sex & Eye & $\begin{array}{l}\text { Age } \\
\text { (years) }\end{array}$ & $\begin{array}{l}\text { Preop } \\
\text { Rx } \\
\text { (SE) }\end{array}$ & $\begin{array}{l}\text { Time after } \\
\text { LASIK } \\
\text { (months) }\end{array}$ & Fellow eye & $\begin{array}{l}\text { Stage } \\
\text { of } \\
\text { MH }\end{array}$ & $\begin{array}{l}\text { Yellow } \\
\text { deposits }\end{array}$ & ERM & $\begin{array}{l}\text { Diameter } \\
\text { of } \mathrm{MH} \\
(\mu \mathrm{m})\end{array}$ & Location & $\begin{array}{l}\text { Cuff of } \\
\text { SRF }\end{array}$ & $\begin{array}{l}\text { PVD } \\
\text { before } \\
\text { LASIK }\end{array}$ & $\begin{array}{l}\text { PVD } \\
\text { after } \\
\text { LASIK }\end{array}$ \\
\hline 1 & $M$ & $\mathrm{~L}$ & 42 & $(-) 0.50$ & 8 & Stage $1 \mathrm{MH}$ & 4 & No & Yes & 400 & Centric & No & No & Yes \\
\hline 2 & $\mathrm{~F}$ & $\mathrm{~L}$ & 30 & $(-) .10 .00$ & 6 & OK & 4 & No & No & 380 & Centric & PPRD & No & Yes \\
\hline 3 & $\mathrm{~F}$ & $\mathrm{~L}$ & 25 & $(-) 4.50$ & 1 & OK & 4 & Yes & No & 400 & Centric & Yes & No & Yes \\
\hline 4 & $\mathrm{~F}$ & $L$ & 57 & $1-19.00$ & 6 & OK & 4 & No & No & 390 & Centric & Yes & No & Yes \\
\hline 5 & $\mathrm{~F}$ & $L$ & 34 & $(-) 9.00$ & 5 & OK & 4 & No & No & 500 & Centric & RRD & Yes & Yes \\
\hline 6 & $\mathrm{~F}$ & $\mathrm{R}$ & 48 & $(-) 8.25$ & 5 & Lattice & 2 & No & No & 200 & Centric & Yes & No & No \\
\hline 7 & $\mathrm{~F}$ & $\mathrm{R}$ & 54 & $(-) 3.50$ & 6 & Lattice & 2 & No & No & 200 & Centric & Yes & No & No \\
\hline 8 & $\mathrm{~F}$ & $\mathrm{~L}$ & 35 & $(-) 7.75$ & 14 & OK & 2 & No & No & 200 & Centric & Yes & No & No \\
\hline 9 & $\mathrm{~F}$ & $L$ & 52 & $(-) 14.50$ & 2 & OK & 4 & No & Yes & 550 & Centric & PPRD & No & Yes \\
\hline 10 & $\mathrm{~F}$ & $\mathrm{~L}$ & 45 & $(-) 7.75$ & 6 & \#15 & 3 & No & No & 500 & Centric & Yes & No & No \\
\hline 11 & $\mathrm{~F}$ & $\mathrm{R}$ & 45 & $(-) 8.75$ & 11 & $\# 14$ & 3 & No & No & 400 & Centric & Yes & No & No \\
\hline 12 & $\mathrm{~F}$ & $\mathrm{R}$ & 52 & $(-) 7.75$ & 18 & VMTS & 2 & No & No & 200 & Centric & Yes & No & No \\
\hline 13 & $\mathrm{~F}$ & L & 53 & $(-) 6.75$ & 12 & OK & 3 & Yes & No & 325 & Centric & No & No & Yes \\
\hline 14 & $M$ & $\mathrm{R}$ & 65 & $1-19.75$ & 83 & OK & 4 & No & No & 750 & centric & PPRD & Yes & Yes \\
\hline
\end{tabular}

$\mathrm{MH}$, macular hole; PPRD, posterior pole retinal detachment; ERM, epiretinal membrane; SRF, subretinal fluid; Rx, refraction; PVD, posterior vitreous detachment; VMTS, vitreomacular traction syndrome; RRD, rhegmatogenous retinal detachment; $S E$, spherical equivalent; $R$, right eye; L, left eye.

to 18 months) after the diagnosis of macular hole. Surgery closed the macular hole on all 14 eyes that underwent surgical management with an improvement on final best corrected visual acuity in 13 out of $14(92.8 \%)$ patients (table 2). The mean follow up after surgery was 17.7 months (3-70 months).

Table 2 outlines detailed characteristics of the macular hole of our case series. The mean diameter of the macular hole was $385.3 \mu$, and the range was from 200 to $750 \mu$. A centric macular hole was found in all eyes. The macular hole was unilateral in 12 of 13 patients (although one of those patients had an impending macular hole (stage 1) in the fellow eye). A stage 4 macular hole was found in seven eyes $(50 \%)$. There was absence of yellow deposits on the retinal pigment epithelium (RPE) of the macular hole in 12 eyes $(85.7 \%)$. Twelve eyes $(85.7 \%)$ lacked a surrounding epiretinal membrane (ERM). Twelve eyes $(85.7 \%)$ had subretinal fluid surrounding the macular hole; four of those eyes (all with
$-10.00 \mathrm{D}$ of myopia) had extensive subretinal fluid in the posterior fundus (table 1).

A vitrectomy closed the macular hole on all eyes with an improvement on final best corrected visual acuity (VA) on 13 out of $14(92.8 \%)$ patients. Poor VA (20/200 or worse) occurred in four $(28.5 \%)$ eyes as a result of associated extensive subretinal fluid in the posterior fundus, and cataract. Six $(42.8 \%)$ eyes out of 14 eyes had a VA outcome of $20 / 100$. Only four $(28.5 \%)$ eyes out of 14 eyes had a VA outcome of 20/40 (table 2).

\section{SELECTED CASE REPORT}

A 30 year old woman (case 2), with $-13.00 \mathrm{D}$ of myopia in the right (RE) and $-10.00 \mathrm{D}$ in the left eye (LE), underwent bilateral laser in situ keratomileusis in June 2001. Six months after surgery, she noted the onset of blurred vision involving her LE. Retinal examination revealed a stage 4 macular hole in the LE (fig IA) associated with a posterior pole retinal

Table 2 Management and visual acuity of patients with surgery for macular holes after LASIK (14 eyes)

\begin{tabular}{|c|c|c|c|c|c|c|}
\hline Patient & Treatment & VA w/MH & Final VA & $\begin{array}{l}\text { F-U } \\
\text { (months) }\end{array}$ & Excimer laser & Microkeratome \\
\hline 1 & Vit + gas & $20 / 50$ & $20 / 25$ & 9 & $\begin{array}{l}\text { Chiron Technolas Keracor } \\
217\end{array}$ & $\begin{array}{l}\text { Chiron automated corneal } \\
\text { shaper }\end{array}$ \\
\hline 2 & Vit + gas & $\mathrm{CF}$ & $20 / 150$ & 4 & Nidek EC-5000 & Nidek MK-2000 \\
\hline 3 & Vit + gas & $20 / 200$ & $20 / 30$ & 7 & Nidek EC-5000 & Nidek MK-2000 \\
\hline 4 & Vit + gas & $20 / 200$ & $20 / 80$ & 4 & $\begin{array}{l}\text { Chiron Technolas Keracor } \\
217\end{array}$ & $\begin{array}{l}\text { Chiron automated corneal } \\
\text { shaper }\end{array}$ \\
\hline 4 & $\sqrt{11}+$ gas & $\angle v /<v 0$ & $20 / 00$ & 70 & & Chiron automated corneal \\
\hline 5 & Vit + gas + laser & LP & $20 / 200$ & & Visx $20 / 20$ & shaper \\
\hline 6 & Vit + gas & $20 / 200$ & $20 / 60$ & $\begin{array}{r}10 \\
6\end{array}$ & Nidek EC-5000 & $\begin{array}{l}\text { Hansatome } \\
\text { Chiron automated corneal }\end{array}$ \\
\hline 7 & Vit + gas & $20 / 200$ & $20 / 40$ & & Nidek EC-5000 & shaper \\
\hline 8 & Vit + gas & $20 / 200$ & $20 / 100$ & 12 & Nidek EC-5000 & $\begin{array}{l}\text { Chiron automated corneal } \\
\text { shaper }\end{array}$ \\
\hline 9 & Vit + gas & $\mathrm{CF}$ & $20 / 400$ & & Visx $20 / 20$ & $\begin{array}{l}\text { Chiron automated corneal } \\
\text { shaper }\end{array}$ \\
\hline 10 & $V i t+I L M+$ gas & $20 / 80$ & $20 / 40$ & 24 & Visx $20 / 20$ & Moria One \\
\hline 11 & $V i t+I L M+$ gas & $20 / 80$ & $20 / 25$ & $\begin{array}{l}20 \\
11\end{array}$ & Visx $20 / 20$ & $\begin{array}{l}\text { Moria One } \\
\text { Chiron automated corneal }\end{array}$ \\
\hline 12 & Vit + Sil Oil & $20 / 80$ & $20 / 200$ & & Nidek EC-5000 & shaper \\
\hline 13 & Vit+ILM+gas & $20 / 100$ & $20 / 50$ & 41 & $\begin{array}{l}\text { Chiron Technolas Keracor } \\
217\end{array}$ & $\begin{array}{l}\text { Chiron automated corneal } \\
\text { shaper }\end{array}$ \\
\hline 14 & Vit+ ILM+ Sil Oil & $\mathrm{HM}$ & $20 / 200$ & 3 & Visx $20 / 20$ & $\begin{array}{l}\text { Chiron automated corneal } \\
\text { shaper }\end{array}$ \\
\hline \multicolumn{7}{|c|}{$\begin{array}{l}\text { LASIK, laser in situ keratomileusis; MH, macular hole; VA, visual acuity; LP, light perception; CF, counting fingers; HM, hand movements; F-U, follow up after last } \\
\text { surgery; w/MH, before macular hole surgery; Vit, vitrectomy; Sil Oil, silicone oil; ILM, internal limiting membrane peeling; Chiron Tecnolas Keracor } 217 \text {, Bausch \& } \\
\text { Lomb Surgical, Inc, San Dimas, CA, USA; Ladar Vision 4000, Alcon Laboratories, Inc, Fort Worth, TX, USA; Nidek EC-5000, Nidek Co, Ltd, Gamagori, Japan; } \\
\text { Coherent Schwind Keratom II, Coherent; Santa Clara, CA, USA; VISX 20/20, VISX USA, Inc, Santa Clara, CA, USA; Chiron automated corneal shaper, Bausch \& } \\
\text { Lomb Surgical, Inc, San Dimas, CA, USA; Carriazo Barraquer, Moria USA, Doylestown, PA, USA; Hansatome, Bausch \& Lomb Surgical, Inc, San Dimas, CA, } \\
\text { USA; Nidek MK 2000, Nidek Co, Ltd, Gamagori, Japan; Moria one, Moria USA, Doylestown, PA, USA. }\end{array}$} \\
\hline
\end{tabular}




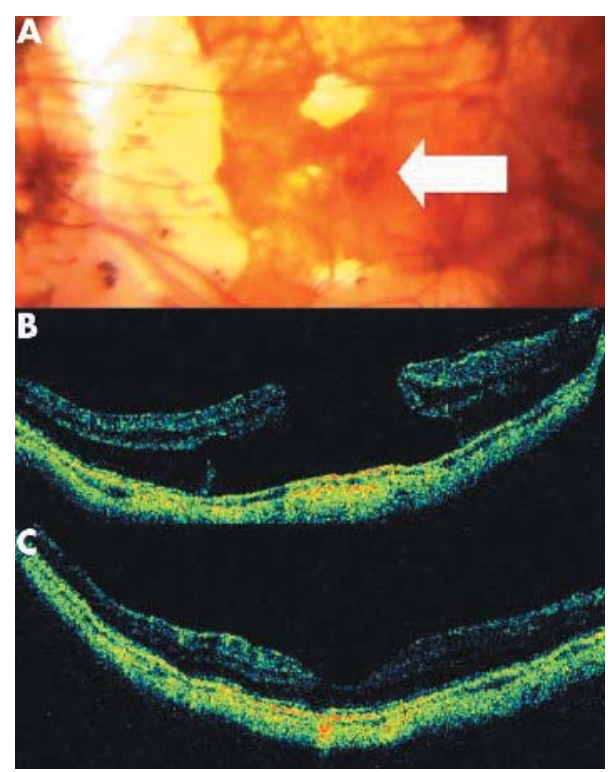

Figure 1 (A) Retinal examination revealed a stage 4 macular hole (arrow) in the left eye associated with a posterior pole retinal detachment, and a best corrected visual acuity (BCVA) of counting fingers. (B) Optical coherence tomography (OCT) image showing features of both foveal retinal detachment and retinoschisis. (C) OCT after vitrectomy reveals a closed macular hole with a BCVA of 20/150.

detachment, and a best corrected visual acuity of counting fingers. OCT image showed features of both foveal retinal detachment and retinoschisis (fig 1B). Best corrected visual acuity recovered to 20/150 with macular hole closure 4 months after successful vitrectomy, and fluid-gas exchange (fig 1C).

\section{DISCUSSION}

Our findings support previous studies that showed the characteristics and demographics of myopic macular holes to be different from those of idiopathic macular holes.

Myopic macular holes tend to develop in young subjects and may be associated with a retinal detachment surrounding the macular hole. ${ }^{14} 15$

In the present series, posterior vitreous detachment was not present before and was documented after LASIK on $42.8 \%$ of eyes. Luna et $a l^{16}$ have used kinetic ultrasonography to demonstrate vitreoretinal alterations after LASIK, including partial or total PVD in 24\% (12 eyes) in high myopes. Their findings are consistent with similar results in almost half of myopic eyes with macular hole after LASIK in our series.

Macular hole surgery can achieve substantial VA improvement for myopic eyes, but the results do not seem to be as favourable as those reported for typical idiopathic macular holes in recent series. ${ }^{17}{ }^{18}$ In our series, only four $(28.5 \%)$ eyes out of 14 had a VA outcome of 20/40. Case 12 was our only case with loss of VA after vitrectomy. However, silicone oil removal and cataract extraction are still pending, and could potentially improve final VA. Our results should be interpreted with caution, since multiple surgeons with different surgical techniques and training participated in this study.

The pathogenesis of macular hole remains controversial. Certainly, vitreofoveal traction is felt to be the predominant force together with pre-existing degenerative changes in the fovea. ${ }^{19}$ Chan and Lawrence ${ }^{10}$ have stated that LASIK surgery has certain features that may induce postoperative vitreoretinal interface changes. For instance, the acute intraocular pressure rise associated with the mechanical stretch of the vitreous base induced by the suction ring as well as the shock waves generated by the excimer laser may lead to vitreoretinal traction. ${ }^{3}{ }^{14}{ }^{15}$ Retinal breaks and detachment have also been reported to occur after laser in situ keratomileusis. ${ }^{3-7}$

Our findings are not generalisable to all myopic eyes that undergo LASIK. However, myopia is a risk factor for macular hole formation. ${ }^{20}$ It is possible that vitreomacular interface changes occurring after laser in situ keratomileusis may predispose certain myopic eyes to form a macular hole. Nevertheless, there are not enough hard data in the literature to determine if these are just myopic holes that would have developed anyway regardless of LASIK.

OCT before LASIK may be helpful to identify those eyes at risk for the development of a macular hole. Chan et al ${ }^{21}$ have recently introduce the concept of a stage 0 macular hole based on OCT observations of the vitreoretinal interface in fellow eyes of patients with unilateral idiopathic macular holes, and to evaluate the subsequent risk of progression to a full thickness macular hole. In a retrospective observational case series of 94 patients with a unilateral stage 2, 3, or 4 full thickness macular hole. They found that in 27 (28.7\%) of 94 clinically normal fellow eyes, OCT detected an abnormality of the vitreoretinal interface but normal foveal anatomy. Eyes with severe and moderate vitreoretinal abnormalities seemed to share characteristic features on OCT that increased their risk of macular hole development (stage 0 macular hole). Univariate analysis revealed that the presence of a stage 0 macular hole was significantly associated with an almost sixfold increase in the risk of macular hole formation (relative risk: 5.8, 95\% confidence interval: 1.16 to 28.61 , $\mathrm{p}=0.03$ ). They concluded that a stage 0 macular hole has a normal biomicroscopic appearance clinically, but has salient features on OCT as a result of oblique vitreous traction. Optical coherence tomographic findings consist of a normal foveal contour and normal retinal thickness and must include the presence of a preretinal, minimally reflective, thin band inserting obliquely on at least one side of the fovea. The presence of a stage 0 macular hole in the fellow eye is a significant risk factor for the development of a second macular hole.

An important limitation of our study is that, owing to its retrospective nature, OCT was not performed before LASIK. In addition, follow up was not consistent and it is possible that patients who developed a macular hole after LASIK were seen by other ophthalmologists outside of our institutions. Thus, we did not attempt to determine the incidence of macular hole formation after LASIK.

In summary, we present 14 eyes of 13 patients with no presurgical sign of a macular hole, which developed a full thickness macular hole after laser in situ keratomileusis. Our study shows that vitreoretinal surgery can be successful in restoring vision for most myopic eyes with a macular hole after LASIK. Vitreoretinal interface changes may have a role in macular hole formation after LASIK for the correction of myopia. Future prospective investigation involving a large number of myopic eyes with ultrasonic or ocular coherence tomographic studies may be valuable for determining vitreoretinal interface changes before and after LASIK.

\section{Authors' affiliations}

J F Arevalo, Retina and Vitreous Service, Clinica Oftalmologica Centro Caracas, Caracas, Venezuela

F J Rodriguez, Fundacion Oftalmologica Nacional (Fundonal), Bogota, Colombia

J L Rosales-Meneses, Unidad Oftalmologica y de Cirugia Vitreo-Retina La Colina, San Cristobal, Venezuela

A Dessouki, Retinal Diagnostic Center, Campbell, CA, USA

C K Chan, Southern California Desert Retina Consultants, Palm Springs, CA, USA 
R A Mittra, VitreoRetinal Surgery, PA Minneapolis, MN, USA J M Ruiz-Moreno, The Vitreo-Retinal Unit, Instituto Oftalmologico Alicante and Miguel Hernandez University School of Medicine, Alicante, Spain

Supported in part by the Fundacion Arevalo-Coutinho para la Investigacion en Oftalmologia (FACO), Caracas, Venezuela.

The authors have no proprietary or financial interest in any products or techniques described in this article.

Correspondence to: J Fernando Arevalo, MD, Clinica Oftalmologica Centro Caracas, Centro Caracas PH-1, Av Panteon, San Bernardino, Caracas 1010, Venezuela; areval $1 @$ telcel.net.ve

Accepted for publication 1 July 2005

\section{REFERENCES}

1 Pallikaris IG, Papatzanaki ME, Siganos DS. A corneal flap technique for laser in situ keratomileusis. Arch Ophthalmol 1991;109:1699-702.

2 Mulhern MG, Condon PI, O'Keefe M. Endophthalmitis after astigmatic myopic laser in situ keratomileusis. J Cataract Refract Surg 1997;23:948-50.

3 Ozdamar A, Aras C, Sener B, et al. Bilateral retinal detachment associated with giant retinal tear after laser-assisted in situ keratomileusis. Retina 1998; 18:176-7

4 Ruiz-Moreno JM, Perez-Santoja JJ, Alio JL. Retinal detachment in myopic eyes after laser in situ keratomileusis. Am J Ophthalmol 1999;128:588-94.

5 Aras C, Ozdamar A, Karacorlu M, et al. Retinal detachment following laser in situ keratomileusis. Ophthalmic Surg Lasers 2000;31:121-5.

6 Arevalo JF, Ramirez E, Suarez E, et al. Incidence of vitreo-retinal pathologic conditions 24 months after laser-assisted in situ keratomileusis (LASIK). Ophthalmology 2000;107:258-62.
7 Arevalo JF, Ramirez E, Suarez E, et al. Retinal detachments after laser-assisted in situ keratomileusis (LASIK) for the correction of myopia. Retina 2000;20:338-341.

8 Luna JD, Reviglio VE, Juarez CP. Bilateral macular hemorrhage after laser in situ keratomileusis. Graefes Arch Clin Exp Ophthalmol 1999;237:611-13.

9 Ruiz-Moreno JM, Perez-Santonja JJ, Alio JL. Choroidal neovascularization in myopic eyes after laser-assisted in situ keratomileusis. Retina 2001;21:115-20.

10 Chan CK, Lawrence II FC. Macular hole after laser in situ keratomileusis and photorefractive keratectomy. Am J Ophthalmol 2001;131:666-7.

11 Ruiz-Moreno JM, Artola A, Perez-Santonja JJ, et al. Macular hole in a myopic eye after laser in situ keratomileusis. J Refract Surg 2002;18:746-9

12 Ruiz-Moreno JM, Alio JL. Incidence of retinal disease following refractive surgery in 9,239 eyes. J Refract Surg 2003;19:534-47.

13 Arevalo JF, Mendoza AJ, Velez-Vazquez W, et al. Macular hole after LASIK. J Refract Surg 2004;20:85

14 Morita $\mathrm{H}$, Ideta $\mathrm{H}$, lto $\mathrm{K}$, et al. Causative factors of retinal detachment in macular holes. Retina 1991;11:281-4.

15 Patel SC, Loo RH, Thompson JT, et al. Macular hole surgery in high myopia. Ophthalmology 2001;108:377-80.

16 Luna JD, Artal MN, Reviglio VE, et al. Vitreoretinal alterations following laser in situ keratomileusis: clinical and experimental studies. Graefes Arch Clin Exp Ophthalmol 2001;239:416-23.

17 Oshima Y, Ikuno Y, Motokura M, et al. Complete epiretinal membrane separation in highly myopic eyes with retinal detachment resulting from a macular hole. Am J Ophthalmol 1998;126:669-76.

18 Seike C, Kusaka S, Sakagami K, et al. Reopening of macular holes in highly myopic eyes with retinal detachments. Retina 1997;17:2-6.

19 Gass JDM. Idiopathic senile macular hole. Its early stages and pathogenesis. Arch Ophthalmol 1988;106:629-639.

20 Kokame GT. Early stage of macular hole in a severely myopic eye Am J Ophthalmol 1995;119:240-242.

21 Chan A, Duker JS, Schuman JS, et al. Stage 0 macular holes: observations by optical coherence tomography. Ophthalmology 2004;1 11:2027-32.

\section{1 th European Forum on Quality Improvement in Health Care}

26-28 April 2006, Prague, Czech Republic For further information please go to: www.quality.bmipg.com Book early to benefit from a discounted delegate rate 